Primljen / Received: 29.2.2016. Ispravljen / Corrected: 30.5.2017.

Prihvaćen / Accepted: 27.11.2017.

Dostupno online / Available online: 10.5.2019.

\section{Comparative study of various smeared crack models for concrete dams}

Autohrs:

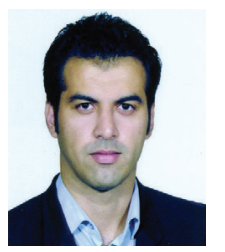

Mehdi Alijani-Ardeshir, MCE

Babol Noshirvani University of Technology

Civil Engineering Departement

Alijani.as@gmail.com

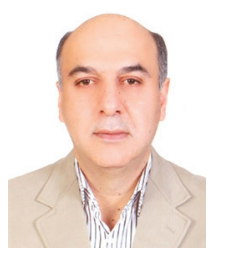

Assoc.Prof Bahram Navayi Neya, PhD. CE Babol Noshirvani University of Technology Civil Engineering Departement Navayi@nit.ac.ir

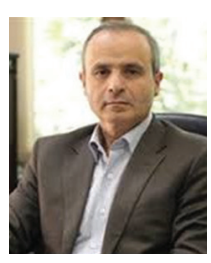

Prof. Mohammadtaghi Ahmadi, PhD. CE Tarbiat Modarre University of Technology Civil Engineering Departement mahmadi@modares.ac.ir
Mehdi Alijani-Ardeshir, Bahram Navayi Neya, Mohammadtaghi Ahmadi

Professional paper

\section{Comparative study of various smeared crack models for concrete dams}

The nonlinear seismic response of concrete gravity dams is investigated in the paper. Nonlinear fracture mechanics based on three smeared crack models is used for comparative study of the cracking profile and dam response. Using the finite element method, the dynamic equation is solved by means of the modified Newton-Raphson method and Bosak's time integration algorithm. The effects of crack models on seismic response of Pine Flat Dam are discussed. The results reveal some differences in principal stress, dam crest displacement, and in the number and shape of cracks.

Key words:
concrete gravity dam, nonlinear dynamic analysis, smeared crack models

Stručni rad

Mehdi Alijani-Ardeshir, Bahram Navayi Neya, Mohammadtaghi Ahmadi

Usporedna analiza različitih modela razmazanih pukotina u betonskim branama

U radu je istražen nelinearni seizmički odgovor betonske gravitacijske brane. Za usporednu analizu profila pukotina i odgovore brane primijenjena je nelinearna mehanika loma triju modela razmazanih pukotina. Primjenom metode konačnih elemenata, dinamička jednadžba je riješena modificiranom Newton-Raphsonovom metodom i Bosakovim algoritmom vremenske integracije. Razmotreni su utjecaji modela razmazanih pukotina na seizmički odgovor brane Pine Flat, a rezultati su pokazali da postoje razlike u glavnim naprezanjima, pomacima krune brane, broju i obliku pukotina.

Ključne riječi:

betonska gravitacijska brana, nelinearna dinamička analiza, modeli razmazanih pukotina

Fachbericht

Mehdi Alijani-Ardeshir, Bahram Navayi Neya, Mohammadtaghi Ahmadi

\section{Vergleichende Analyse unterschiedlicher Modelle betrachteter Risse in} Betondämmen

In der Abhandlung wurde die nicht lineare seismische Antwort des Gravitationsdamms aus Beton untersucht. Für die vergleichende Analyse der Rissprofile und die Antworten des Damms wurde bei drei Modellen die nicht lineare Bruchmechanik der verschmierten Risse angewendet. Durch Anwendung der Finiten-Elemente-Methode wurde die dynamische Gleichung durch die modifizierte Newton-Raphson-Methode und Bosak's Algorithmus der Zeitintegration gelöst. Betrachtet wurden die Auswirkungen der Modelle der verschmierten Risse auf die seismische Antwort des Damms Pine Flat, und die Ergebnisse zeigten, dass es Unterschiede in den Hauptspannungen, der Verschiebung der Dammkrone, der Anzahl und der Form der Risse gab.

Schlüsselwörter:

Gravitationsdamm aus Beton, nicht lineare dynamische Analyse, Modelle betrachteter Risse 


\section{Introduction}

The safety and stability of concrete dams during earthquakes has widely been studied by various researchers. Over the past eight decades, authors have conducted comprehensive seismic analyses on the dam-reservoir systems using different methods, one of the most notable being the FEM (Finite Element Method), and have considered different parameters such as water compressibility, dam-reservoir interaction, crack in dam body, etc. In the dynamic analysis of concrete dams, the interaction effect of reservoir can be represented by three basic approaches including the added mass, Eulerian approach, and Lagrangian approach. The added mass is the simplest approach that assumes the effect of reservoir approximated as an added mass attached to the dam. In Eulerian approach, the variables in the reservoir are expressed by the pressures or velocity potential and the structural variables are displacements. Since these two types of variables are different from each other, a special algorithm is required for the solution of the coupled system [1].

In Lagrangian approach, the behaviour of structure and fluid is represented in terms of displacements or velocity of the finite element mesh nodes, and some constrains and penalty functions are suggested to eliminate the spurious modes in the fluid [2-5]. Concrete gravity dams are likely to experience cracking due to low tensile strength of concrete and, as a result, nonlinear analysis of concrete dams will be inevitable. To understand the nonlinear behaviour of concrete dams, it is necessary to model the cracking and damage process. Over the past 35 years, extensive research has been carried out and researchers have introduced different crack models for studying behaviour of fractured concrete. Two classes of models based on the Discrete Crack and Continuum Crack models can be found in nonlinear study of concrete gravity dams. The Discrete Crack Model requires response monitoring and modification of the finite element mesh in accordance with crack configurations that occur at each loading phase. However, this approach explicitly shows the crack as a separation of two adjacent nodes in the finite element mesh that represents a more realistic simulation of crack opening. This model is applicable when the location and direction of cracks are discernible before load is applied on the structure $[6,7]$. The use of the discrete crack model in fracture analyses of mass concrete dams remains limited because of tremendous computational costs [7]. Two methods can be used in the discrete crack model, i.e. the linear elastic fracture mechanics (LEFM) and the nonlinear fracture mechanics (NLFM). The discrete crack model with the LEFM has been applied in the past to investigate the static fracture response of concrete dams [7]. The LEFM analysis is applicable to a material with a negligible fracture process zone (FPZ).

The concrete material of the dam appears to have a limited similarity with LEFM due to considerably large FPZ in relation to the dimensions of concrete gravity dams. This phenomenon is more critical around the dam neck [7, 8]. Ahmadi and Razavi
[9] represented a finite element model of discrete cracks for modelling joints. They considered perfectly elasto-plastic behaviour for joint in tension, and linear elastic behaviour in compression and shear. Ahmadi et al. [10] introduced a nonlinear joint element with coupled tension-shear behaviour for the analysis of arch dams. Lotfi and Espandar [11] used the discrete crack method, non-orthogonal smeared crack, and combination of them, for seismic analysis of dams.

The Continuum Crack Model is divided into the damage mechanics approach and the smeared crack model. Ghrib and Tinawi [12] used the anisotropic damage mechanics model in the nonlinear seismic analysis of concrete gravity dams. The model is capable of representing the opening and closing of cracks using element properties such as the compressive and tensile strength, and fracture energy. Some researchers such as Gunn [13], Valliappan et al. [14], Sumarac et al. [15], Labadi and Hannachi [16], Contrafatto and Cuomo [17], Grassl and Jirasek [18], Khan et al. [19] and Mirzabozorg et al. [20], applied damage mechanics to study behaviour of concrete. Also, Ardakanian et al. [21] considered nonlinear seismic behaviour of mass concrete in 3D analysis based on an anisotropic damage mechanics model. In the smeared crack model, cracks are modelled by appropriately modifying material properties. Smeared cracks are convenient when the crack orientations are not known beforehand, because the formation of a crack involves no re-meshing or new degrees of freedom.

A tensile strength-based crack propagation analysis (Rashid [22]) is generally considered as an unreliable approach due to the mesh-dependent response prediction [23, 24]. The nonlinear behaviour in the FPZ, being significantly large for the concrete body of dams, is neglected in the conventional LEFM models. Under very slowly applied loads as well as under impulsive loads, the LEFM models appear to be capable of adequately predicting the concrete fracture behaviour. For short-term static loads and seismic-induced loads, NLFM models appear to be more appropriate as they take into account the strain softening behaviour in the FPZ [25].

The strain softening crack band constitutive model, derived on the basis of the fracture energy conservation principle, is regarded as a significant achievement in the finite element analyses of concrete fracture problems. The strain softening of the material based on the NLFM parameters included different crack models, failure criteria, different fracture modes, etc. [23]. However, the fracture propagation direction has not been precisely addressed in the crack band model. In most practical fracture problems, shear deformations in strain softening elements may cause rotation of crack bands. Crack constitutive models, which fix the local crack band at the initial inclination, generally lead to a severe stress locking due to the zigzag propagation of crack profiles in a continuous finite element mesh. De Borst and Nauta [26, 27] proposed a constitutive framework which allows non-orthogonal multiple crack formulations to alleviate the stress locking in smeared crack analyses. The non-orthogonal formulation 
may result in ill-conditioned stiffness matrices due to close angular spacing of cracks in a finite element. By applying the rotating crack concept together with an implicit definition of the softened shear resistance of finite elements, the stress locking may be alleviated in smeared crack analyses [28, 29]. By using a nonlocal constitutive model, the directional sensitivity of the crack band propagation in tilted finite element meshes may be eliminated [30]. However, the application of the nonlocal model in dam fracture analyses is limited. This is attributed to the requirement of an extremely fine mesh (at least three elements on a crack band) and also to the high computational costs associated with the spatial averaging of local response quantities. It has been established that the localized smeared crack models are very promising for applications in complex structural analyses, which is due to significantly lower computational costs and a simplified definition of the constitutive behaviour of material. Furthermore, the extension of local band fracture models to transient and three-dimensional analyses has proven to be relatively simpler $[6,7]$.

Bhattacharjee and Leger [6] studied the dynamic fracture response of Koyna Dam by applying the coaxial rotating crack model and the fixed crack model with a variable shear resistance factor in concrete model. In their analysis, the foundation was assumed to be rigid, and the results showed the formation of cracks at the base and at the upper portion near the point of downstream slope change for the Koyna earthquake.

Failure based on the smeared crack model was studied by many other researchers such as Ghaemian \& Ghobarah [31], Vaseghi Amiri \& Ahmadi [32], Weihe et al. [33], Mosler \& Meschke [34], Cai [35], Lotfi et al. [36], and Calayir \& Karaton [25], but none of these researches had the same result for the path of crack propagation with the observed prototype behaviour.

Mirzabozorg and Ghaemian [37] developed a model based on the smeared crack model in 3D models including the dam-reservoir interaction. Mirzabozorg et al. [38] investigated non-uniform cracking in the smeared crack model for 3D analysis of concrete dams. Mirzabozorg et al. [39] studied nonlinear behaviour of concrete dams under nonuniform earthquake records.

A numerical scheme based on the non-linear crack band theory was used by Guanglun et al. [40] to investigate the seismic fracture behaviour of Koyna Dam under the Koyna earthquake. The analysis of the dam with rigid foundation showed that cracks appeared at the upper portion of the dam near the point of change in downstream slope.

Kalani et al. [5] studied the 2D seismic fracture behaviour of concrete gravity dams under nonuniform earthquake and rotational and translational components of earthquake using the orthogonal multi fixed smeared crack.

Apparently, the fracture response of concrete dams with different smeared crack models has not been compared using the state of the art continuum mechanics models.

The main objective of this paper is to present a comparative study of different smeared crack models, namely:
- the multidirectional fixed crack model (MFCM)

- the coaxial rotating crack model (CRCM)

- the orthogonal multi fixed crack model (OMFCM), in the 2D dynamic analysis of concrete dams.

\section{Constitutive models for fracture analysis}

When the maximum principal stress exceeds that of tensile strength, the fracture process is initiated in smeared crack models. The shape of the tensile-softening diagram mainly controls the crack propagation, and the energy absorbed in the crack band of the softening zone per unit cross-section area is defined as the fracture energy $G_{f}$ which is a characteristic parameter of the material. In this research, the following four steps are considered to study the fracture behaviour of gravity dam concrete: crack initiation criterion, strain softening, post cracking behaviour, and the closing-reopening of crack. The pre-cracking behaviour of concrete is assumed to be linear and elastic and stresses $\{\sigma\}$ and strains $\{\varepsilon\}$ are related as:

$\{\sigma\}=[D]\{\varepsilon\}$

Where $[D]$ is the constitutive relation matrix and is defined for an isotropic plane stress condition as:

$[D]=\frac{E}{1-v^{2}}\left[\begin{array}{ccc}1 & v & 0 \\ v & 1 & 0 \\ 0 & 0 & \frac{1-v}{2}\end{array}\right]$

where, $\mathrm{E}$ and $\mathrm{v}$ are the modulus of elasticity and Poisson's ratio, respectively.

Finite element analysis has a linear elastic relationship until the tensile strain energy density, $1 / 2 \sigma_{1} \varepsilon_{1}$, where $\sigma_{1}$ and $\varepsilon_{1}$ are the principal stress and strain values, respectively. It becomes equal to the pre peak area under a uniaxial stress-strain diagram, usually determined from experimental tests (Figure 1).

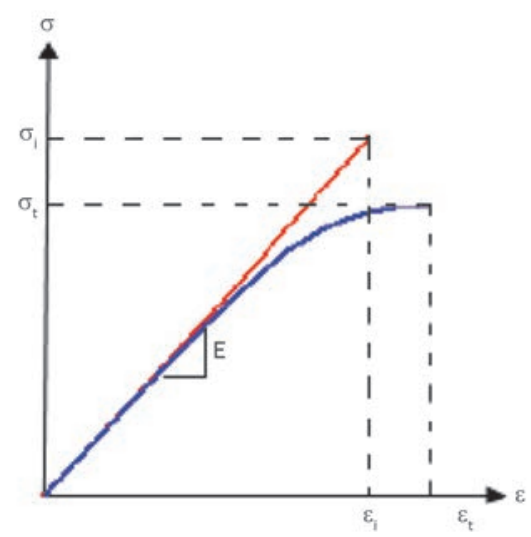

Figure 1. Tensile stress-strain behaviour of concrete material [35] 
To consider the nonlinearity of concrete and also the effect of two axial stresses, the crack initiation criterion using the tensile strain energy can be written with Eq. (3), as follows [32]:

$$
\frac{\sigma_{1}}{\sigma_{2}}=\left(\frac{\sigma_{1}}{\sigma_{1}-v \sigma_{2}}\right)^{\frac{1}{2}}
$$

Where $\sigma_{1}=1.3 \sigma_{t}$ and $\sigma_{t}$ is the uniaxial tensile strength of the concrete [5].

Thus, when the maximum principal stresses at a Gauss point of an element satisfy Eq. (3), the first crack is assumed to be formed in the element perpendicularly to the maximum principal stress, as shown in Figure 2.

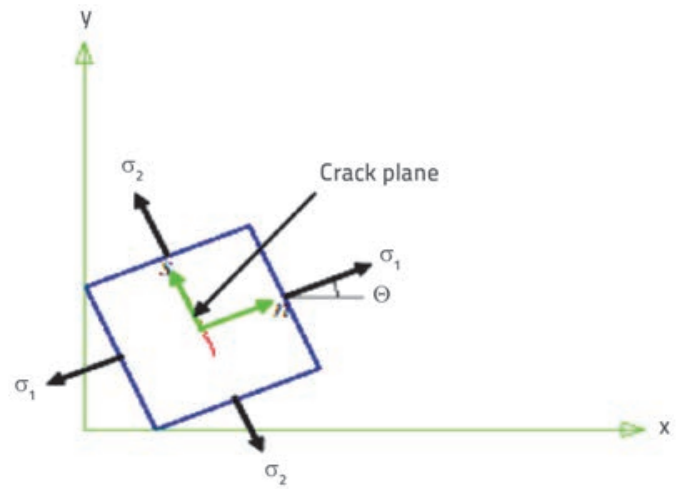

Figure 2. Crack element and local coordinates [35]

After crack initiation, the concrete behaves like a strain softening material. , for which as the strain increases, the tensile stress normal to the crack decreases. The strain softening relation can be derived from uniaxial tensile tests of a concrete specimen with deformation control.

As shown in Figure 3, for the complete stress-strain relation, $E_{1} E_{t}$ and $E_{s}$ are the initial modulus, the current secant modulus, and the tangential modulus, respectively and $e_{n}$ is the local strain which is decomposed into the crack strains $e^{\text {cr }}$ and the concrete strains $e^{c o}$.

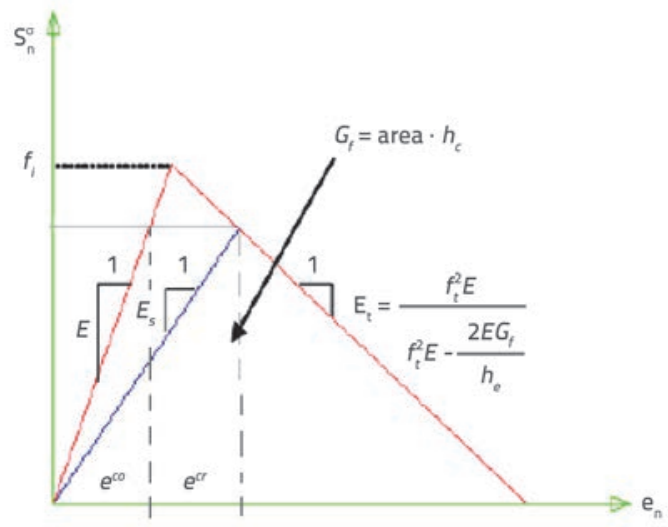

Figure 3. Complete stress-strain behaviour of concrete material in tension [35]
The slope of the softening curve is adjusted in such a way that the energy dissipation for a unit area of crack plane propagation $G_{f}$ is conserved. The fracture energy $G_{f}$ can be evaluated with Eq. (4), from [32]:

$G_{f}=h_{c} \int S_{n}^{c r} d e_{n}$

In which, $h_{c}$ represents the crack band width of the fracture process zone given by the characteristic length of the material; for concrete it is suggested $h_{c}=3 d$ where $d$ denotes the maximum aggregate size in concrete [35]. In the finite element analysis, when the size of the element modelling the crack band width becomes greater than $h_{c^{\prime}}$ the softening constitutive curve needs to be modified in accordance with the Bezant's energy criterion [35] so that the fracture energy remains the same. Thus, the results remain independent of the element size.

As shown in Figure 4, in dynamic analyses, the initial modulus and the tensile strength are increased using the coefficients 1.25 and 1.5 , respectively [32].

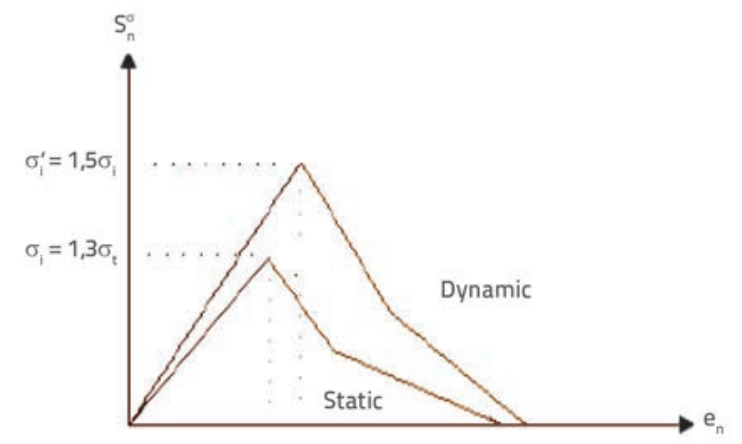

Figure 4. Static and dynamic softening curve [5]

To consider the size effect of the structure and a more realistic model to match the experimental results, the shape of softening curve can also be changed in bilinear form as shown in Figure 5.

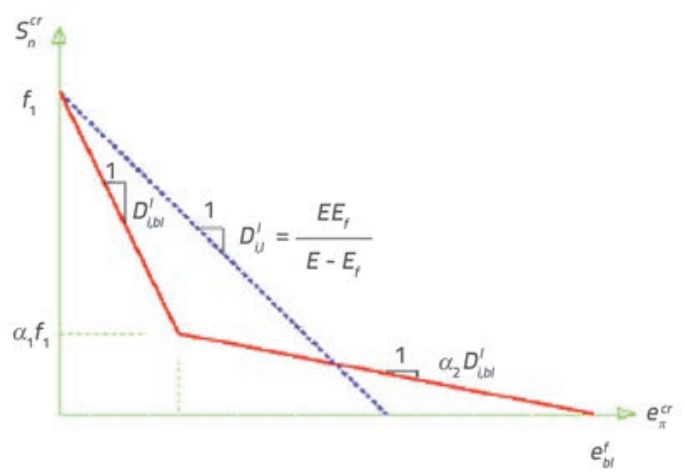

Figure 5. Stress-strain multi-linear behaviour after cracking [35]

In Figure 5, $D_{i, b l}^{\prime}$ is expressed with Eq. (5) as:

$D_{i, b l}^{\prime}=\frac{\alpha_{1}+\left(1-\alpha_{2}\right) \alpha_{1}^{2}}{\alpha_{2}}\left(-\frac{f_{t}^{2} h_{c}}{2 G_{f}}\right)=\frac{\alpha_{2}+\left(1-\alpha_{2}\right) \alpha_{1}^{2}}{\alpha_{2}} D_{i, l}^{\prime}$ 
where, $\alpha_{1}$ and $\alpha_{2}$ are obtained using experimental results [35]. If $\alpha_{1}=0$ or the $\alpha_{2}=1$, then $D_{i, b l}^{\prime}=D_{i, 1}^{\prime}$ resulting in linear softening behaviour [5].

The stress-strain relation for a concrete element undergoing cracking is given by Eq. (6):

$\left\{S_{n}^{c r} S_{s}^{c r} \tau_{n s}\right\}^{T}=[D]_{n s}\left[e_{n} e_{s} \gamma_{n s}\right]^{T}$

where subscripts $n$ and $s$ represent local coordinates in accordance with the crack direction shown in Figure 2. $[D]_{n s}$ represents the material property matrix for the same local coordinate orientation and is given by Eq. (7), from [5]:

$$
D_{n s}=\frac{E}{1-\mu v^{2}}\left(\begin{array}{ccc}
\mu & \mu v & 0 \\
\mu v & \mu & 0 \\
0 & 0 & \beta \frac{1-\mu v^{2}}{2(1+v)}
\end{array}\right)
$$

where $\mu=E_{s} / E$ is the ratio between the secant and initial modulus and $b$ is the shear retention factor representing the extent of aggregate interlock on the crack surfaces. For the multi fixed crack model, $\beta$ it is obtained using Eq. (8), by [35]:

$\beta=\beta_{\max }\left(1-\frac{e_{n m}^{c r}}{e_{n}^{f}}\right)^{p}$

where, $e_{n m}^{c r}$ and $e_{n}^{f}$ are the crack strain and total crack strain, $\beta_{\max }$ is the maximum shear retention factor for the cracked element. For coaxial rotating crack model, the shear retention factor is obtained using by Eq. (9), by [32]:

$\beta=\frac{1+v}{1-\mu v^{2}}\left(\frac{\mu \varepsilon_{n}-\varepsilon_{s}}{\varepsilon_{n}-\varepsilon_{s}}-\mu v\right)$

Where, $\varepsilon_{\mathrm{n}}$ and $\varepsilon_{\mathrm{s}}$ are strain components in the directions normal and parallel to the fracture plane, respectively.

The definition of shear resistance factor variable according to (9), which takes into account deformations in both the lateral and normal directions to a fracture plane, is different from that of the usual formulations in which only the crack normal strain is often considered as the damage index.

In CRCM, the local axis n-s is always kept aligned with the directions of principal strains, while in MFCM, the strains of the local axis system are not necessarily coaxial with the principal stress directions. In MFCM, the local axis system is first aligned with the principal strain directions at the moment of softening initiation, and is then kept fixed for the rest of the analysis. The mixed mode fracturing behaviour due to both tensile and shear stress conditions leads to rotation of principal stress axes when a crack is formed [27]. Consequently, the fixed crack axes no longer represent the principal stresses axes.

In this paper, a new crack is initiated whenever the tensile principal stresses violate the crack initiation criterion, and whenever the angle between the current principal stress direction, normal to the crack plain of the last crack, exceeds a threshold angle. The threshold angle is an arbitrary angle that is not determined before, and its value should be obtained to see what angle is appropriate for a threshold angle. Depending on the different value of threshold angles for MFCM model, many cracks could occur at a gauss point and, in order to study its value, six threshold angles including 5, 10, 15, 20, 25, and 30 degrees, are considered. Also, a maximum of four cracks are allowed to form at a gauss point.

The local constitutive relationship matrix $[D]_{\text {ins }}$ can be transformed to the global coordinate directions as follows [5]:

$[D]_{x y}=[T]^{T}[D]_{n s}[T]$

where $[T]$ is the transmitting matrix from the local to global axis.

During the seismic load, the cracks may close and reopen both periodically and progressively. As shown in Figure 6, the simplified constitutive model for cracks closingreopening is adopted based on the tensile cyclic tests given in [5]. The element behaves linearly before cracking and also subsequently after the crack closes (with modulus E).

Whenever the strain normal to the crack surface becomes positive again (tensile stress), the crack reopens with a decreasing secant modulus $E_{5}$ until the normal strain, which is equal to the total crack strain $\left(e_{n}=e_{n}^{f}\right)$.

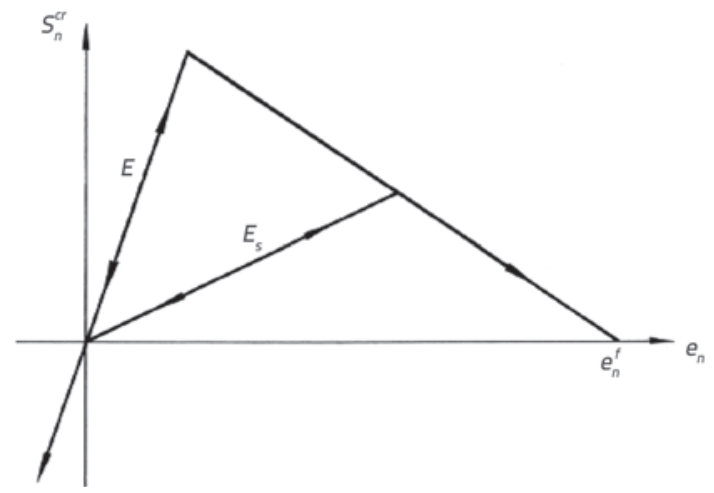

Figure 6. Closing-reopening behaviour of concrete material [5] 


\section{Lagrangian formulation for interaction of dam-reservoir system}

In this paper, the equation of motion of the dam-reservoir system is solved using the Lagrangian-Lagrangian approach considering the linear, elastic, irrotational and inviscid fluid. Based on Lagrangian approach, F.E. equation of motion for the fluid domain is expressed by Eq. (11), from [5]:

$M_{f} \ddot{U}_{f}+C_{f} \dot{U}_{f}+K_{f} U_{f}=F_{f}(t)$

Where $M_{f} C_{f} K_{f} \dot{U}_{f}, \ddot{U}_{f}$ and $U_{f}$ are the fluid mass matrix, damping matrix, stiffness matrix, the nodal acceleration, velocity and displacement vectors of F.E. mesh, respectively. $F_{f}(t)$ is the timevarying nodal force vector defined as $\mathrm{M}_{\mathrm{f}} \mathrm{a}_{\mathrm{g}}$ when the earthquake ground acceleration $\mathrm{a}_{\mathrm{g}}$ is applied to the fluid.

The stress-strain relationships undergoing a small amplitude motion for 2D fluid element can be written by Eq. (12), by [25, 5]:

$$
\left\{\begin{array}{l}
P \\
P_{w}
\end{array}\right\}=\left[\begin{array}{cc}
C_{11} & 0 \\
0 & C_{22}
\end{array}\right]\left\{\begin{array}{l}
\varepsilon_{v} \\
w
\end{array}\right\}
$$

where $P, \varepsilon_{v^{\prime}} C_{11}$ are the pressure, volumetric strain, and bulk modulus of the fluid, $w$ is the rotation about the normal to the plane, $P_{w}$ and $C_{22}$ are stress and constraint parameter related with $w$, respectively $[4,5,25]$.

Rotation and constraint parameters are included in the stressstrain equation of the fluid, since the fluid irrotational constraint is considered by penalty function. A reduced integration order with four integration points is utilized in formation of the stiffness matrix of nine node quadrature fluid elements [4, 5]. The Somerfield boundary condition is used for radiation condition in truncated far end of the reservoir [4, 31]. The nodal points along the normal direction at the truncated boundary and bottom of reservoir are assumed to have a zero displacement.

The interface condition between the dam reservoir surfaces must be determined to take into account the dam-reservoir interaction. Since the fluid is assumed to be inviscid, only the displacements along the direction normal to the interface are continuous, and this condition is imposed by the penalty function satisfied using the interface elements with the stiffness matrix $\mathrm{K}_{\text {int }}$. The six-node element with three integration points is used in interface elements of the system [5]. Using the interface condition, the equation of motion of the coupled dam-reservoir system subjected to ground motion is given as follows [5].

$M_{c} \ddot{U}_{c}+C_{c} \dot{U}_{c}+K_{c} U_{c}=F_{c}(t)$

where, $M_{c^{\prime}} C_{c}$ and $K_{c}$ are the mass, damping and stiffness matrices for the coupled system. $U_{c^{\prime}} \dot{U}_{c}$ and $\ddot{U}_{c}$ are the vectors of the displacement, velocity, and acceleration of the coupled system, and $F_{c}(t)$ is the time-varying nodal forces vector of ground acceleration.
The damping matrix $C_{c}$ is defined as the sum of internal damping and radiation damping. The internal damping is assumed to be proportional to the stiffness $\beta_{1}[K]$, where $\beta_{1}$ is determined by specifying the desired damping ratio at a certain frequency and $[K]$ is the structural or fluid element stiffness matrix. $b_{1}$ is determined by applying the damping ratio of $5 \%$ for structural element and damping ratio of $0.1 \%$ for fluid element $[4,5,25]$. Nine node iso-parametric plane stress elements with full integration point are considered for dam elements.

In this paper, the governing equation of the dam-reservoir system is solved by the Bosak's method. For nonlinear analysis, the forces and displacements at nodes of the finite element mesh are selected for convergence criteria in the Newton-Raphson iteration technique in order to minimize the unbalance between the adjustable applied loads and the restoring forces of the system.

\section{Numerical results}

Several investigators over the decades considered the Pine Flat dam, to study the application of the smeared crack models. In this paper, the nonlinear dynamic analysis of the tallest monolith of the Pine Flat dam is performed by considering the dam-reservoir interaction. Geometrical characteristics and the finite element mesh for the tallest monolith of the dam and its reservoir are shown in Figure 7, and two elements on the FE mesh of the dam are marked, for which the time history graph of the response is plotted. These elements are elements No. 8 at the heel of the dam base and No. 177 at the dam neck.

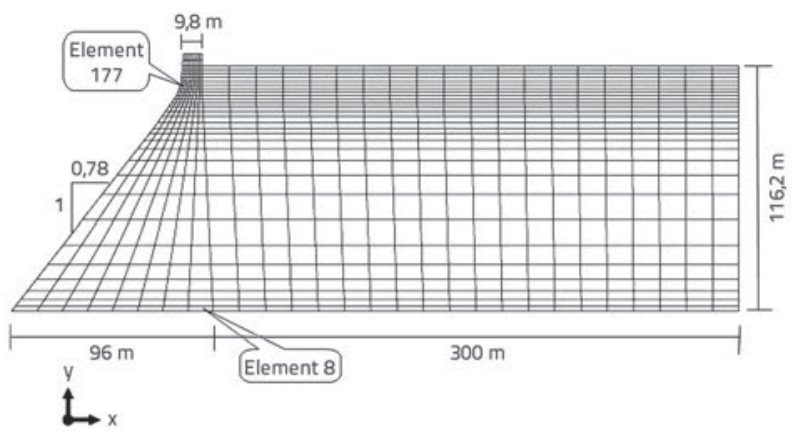

Figure 7. Dimensions of tallest monolith of Pine Flat dam and its finite element mesh

Maximum water level in the reservoir is $116.2 \mathrm{~m}$ and the reservoir length is considered to be three times as long as the water level $(B=3 h)$ while the foundation is assumed to be rigid. Material properties adopted in the analysis are shown in Table 1 [31, 32]. The bilinear softening curve of Cai [35] has been used to obtain the fracture results using $\alpha_{1}=0.3$ and $\alpha_{2}=0.2$. The horizontal and vertical acceleration components of Taft earthquake (1952) are selected and assumed to act in streamwise and vertical directions of the dam-reservoir system, respectively. The records of this ground motion and its characteristics are shown in Figure 8 and Table 2. Based on the sensitivity analysis, the integration time step of $0.002 \mathrm{sec}$ has been adopted. 
Table 1. Material properties of Pine Flat dam

\begin{tabular}{|c|c|c|c|c|c|}
\hline Material & $\begin{array}{c}\text { Bulk modulus K } \\
{[\mathrm{MPa}]}\end{array}$ & $\begin{array}{c}\text { Tensile strength Ft } \\
{[\mathrm{MPa}]}\end{array}$ & $\begin{array}{c}\text { Poisson's } \\
\text { ratio }\end{array}$ & $\begin{array}{c}\text { Damping } \\
\text { ratio }\end{array}$ & $\begin{array}{c}\text { Fracture energy G } \\
{[\mathrm{N} / \mathrm{m}]}\end{array}$ \\
\hline Concrete & 15556 & 2.0 & 0.2 & 0.05 & 150 \\
\hline Water & 2070 & - & - & 0.01 & - \\
\hline
\end{tabular}

Table 2. Characteristics of earthquake

\begin{tabular}{|c|c|c|c|c|c|}
\hline Component & Station & Magnitude (Rishter) & Epicentral distance & PGA [g] & Shear velocity \\
\hline Horizontal-S69E & \multirow{2}{*}{$\begin{array}{l}\text { Lincoln } \\
\text { school }\end{array}$} & \multirow[b]{2}{*}{7.36} & \multirow[b]{2}{*}{$35[\mathrm{~km}]$} & 0.179 & \multirow{2}{*}{385.4} \\
\hline Vertical & & & & 0.155 & \\
\hline
\end{tabular}

Table 3. Natural frequency of system (rad/s)

\begin{tabular}{|c|c|c|c|c|}
\hline Mode & $\mathbf{1}$ & $\mathbf{2}$ & $\mathbf{3}$ & $\mathbf{4}$ \\
\hline Dam & 20.04 & 41.2 & 55.41 & 70.99 \\
\hline Dam and reservoir & 12.93 & 19.98 & 20.38 & 24.09 \\
\hline
\end{tabular}

In order to perform the linear and nonlinear dynamic analysis of the dam-reservoir system, a computer code is written in Fortran 91 by the authors. In all calculations, tensile strains and stresses are displayed with positive value.
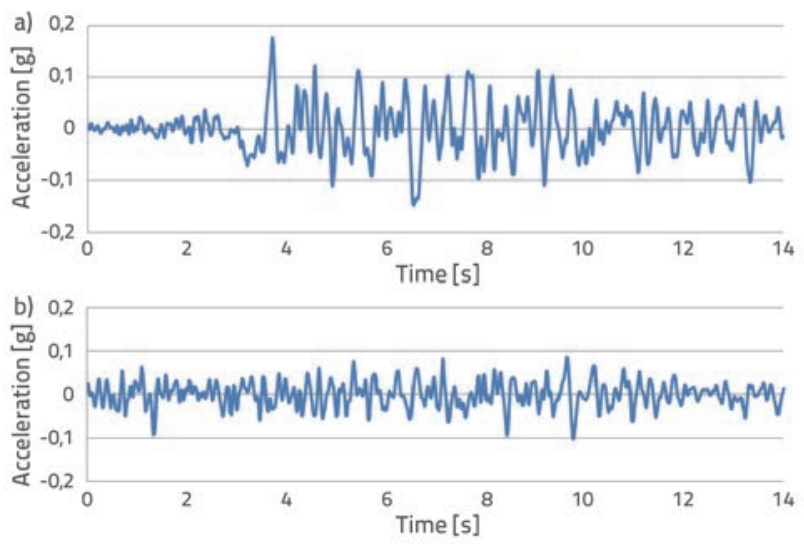

Figure 8. Taft earthquake acceleration, a) S69E component, b) vertical component

\subsection{Verification}

The linear horizontal responses of Pine Flat dam crest with impounded and with an empty reservoir due to S69E component of Taft earthquake, which are obtained in present work, are compared with the results obtained in [41].

These results are shown in Figure 9, and the agreement between the results is satisfactory. Some differences in results are referred to modelling of dam and reservoir with the 4-node element and semi-infinite element of reservoir and use of coarse element in $[4,41]$.
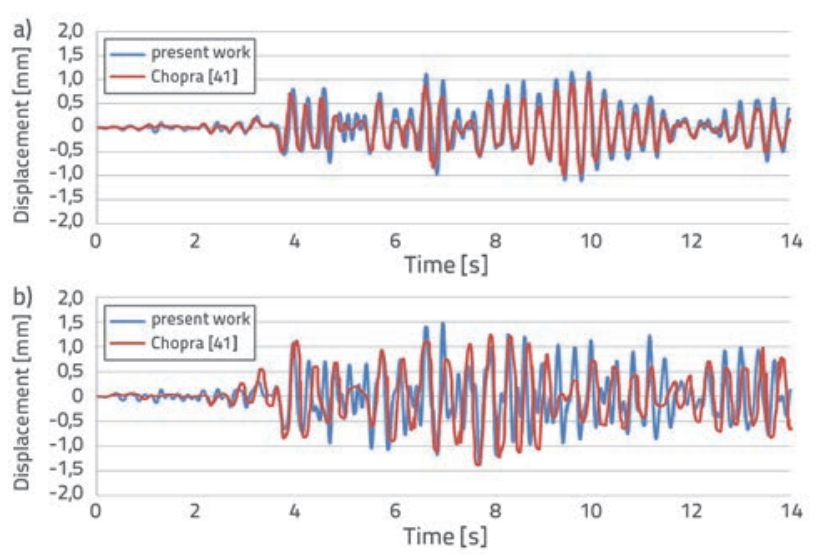

Figure 9. Linear horizontal response of Pine Flat dam crest due to S69E component of Taft earthquake, a) Dam with an empty reservoir, b) Dam with impounded reservoir

\subsection{Response of Pine Flat dam}

Nonlinear responses of the dam-reservoir system under seismic loading are compared in this paper, taking into account the cracking effect of the concrete material due to different smeared crack models. All analyses conducted in the paper refer to two cases:

- Dam with an empty reservoir and without hydrostatic pressure of reservoir,

- Dam with impounded reservoir and with the fluid-structure interaction (FSI) effect.

The static responses are taken as initial conditions for the dynamic analysis of the system. In the case of the dam with an empty reservoir, initial stresses should be calculated taking into account the 
dam body force only, while for the dam with an impounded reservoir, the loads are dam body force and hydrostatic pressure. Meanwhile the temperature effect is not taken into account in this paper.
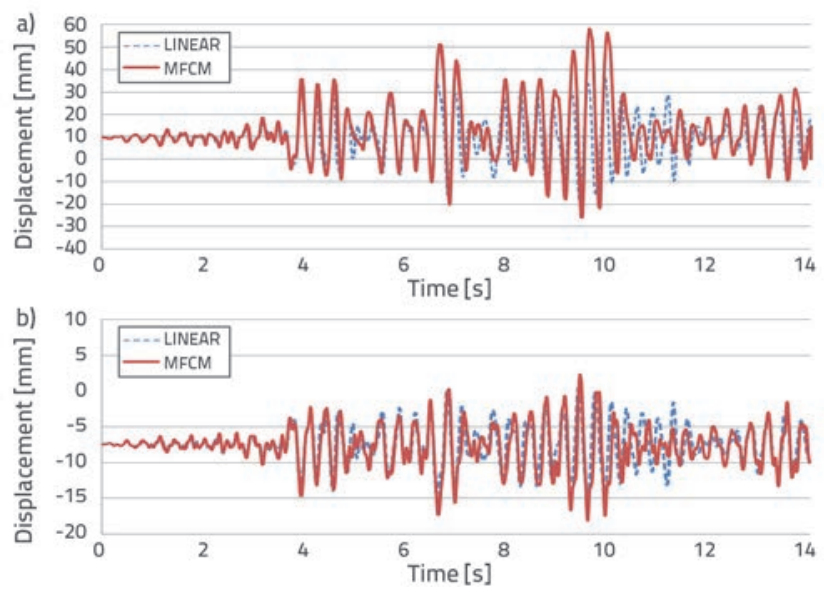

Figure 10. Crest displacement with empty reservoir (MFCM) and with threshold angle of $5^{\circ}:$ a) horizontal; b) vertical
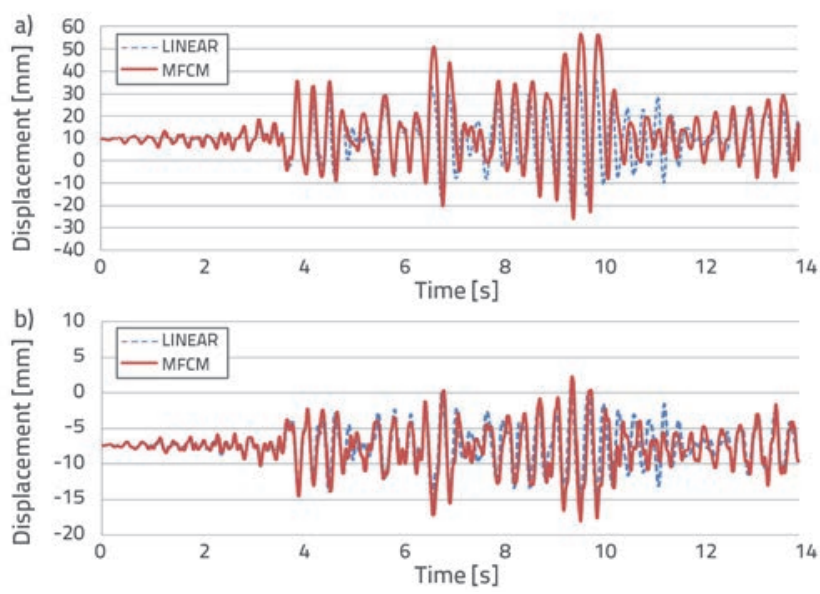

Figure 12. Crest displacement with empty reservoir (MFCM) and with threshold angle of $15^{\circ}:$ a) horizontal; b) vertical
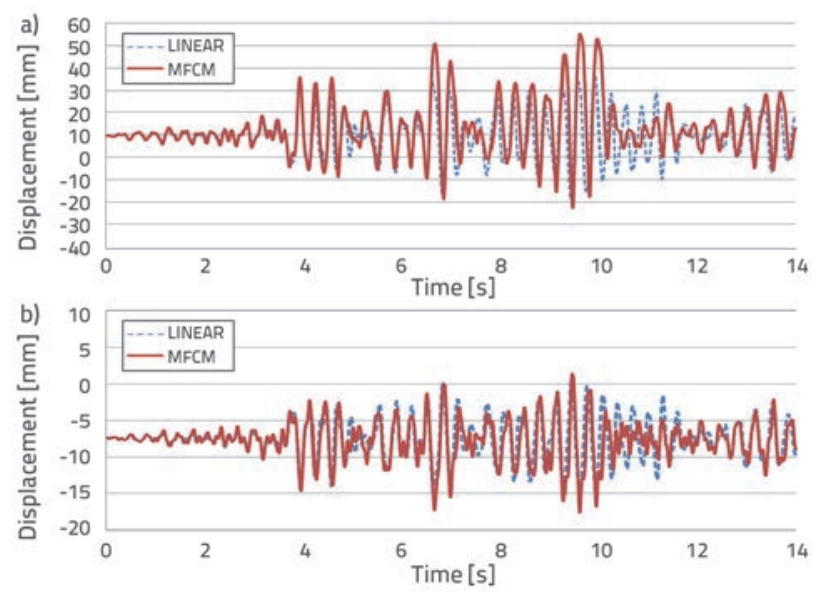

Figure 14. Crest displacement with empty reservoir (CRCM): a) horizontal; b) vertical
The displacement time history of the dam crest, using different crack models with an empty reservoir, is shown in Figures 10 to 16 .
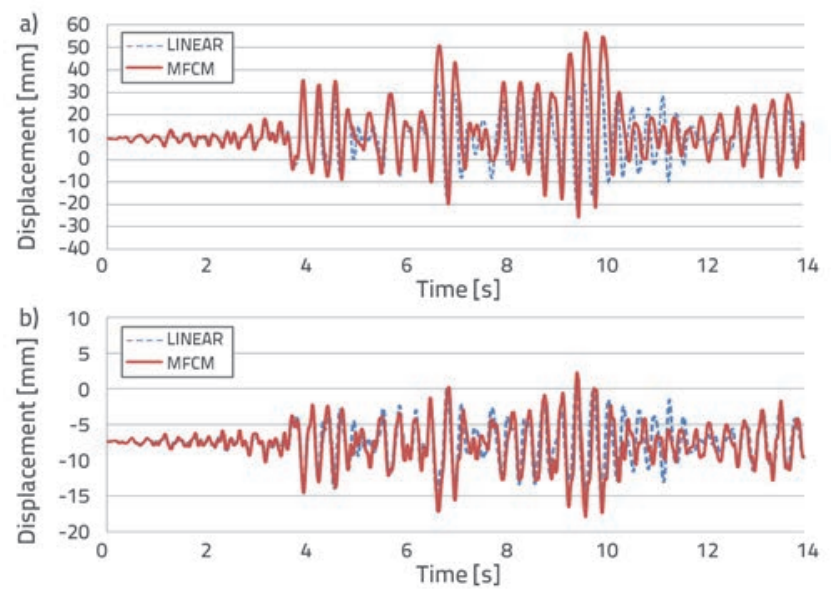

Figure 11. Crest displacement with empty reservoir (MFCM) and with threshold angle of $10^{\circ}:$ a) horizontal; b) vertical
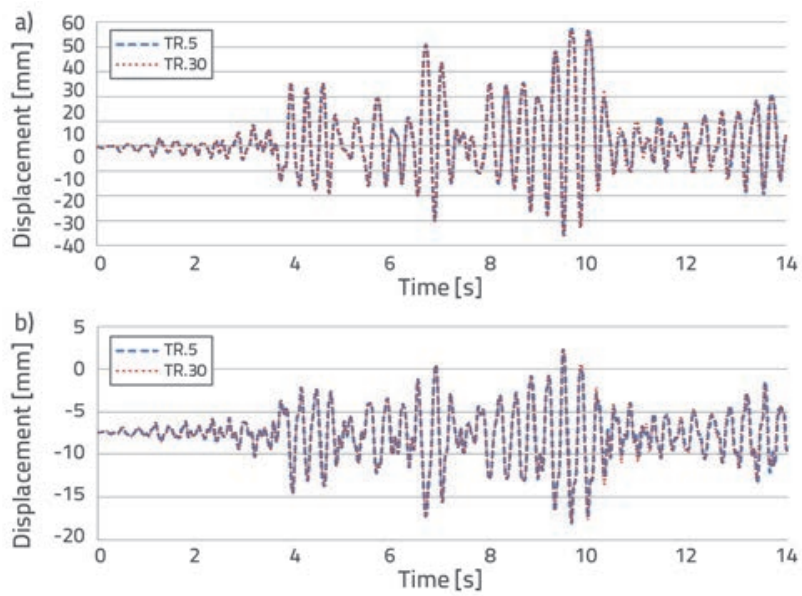

Figure 13. Crest displacement with empty reservoir (MFCM) and with threshold angles of $5^{\circ}, 30^{\circ}:$ a) horizontal, b) vertical
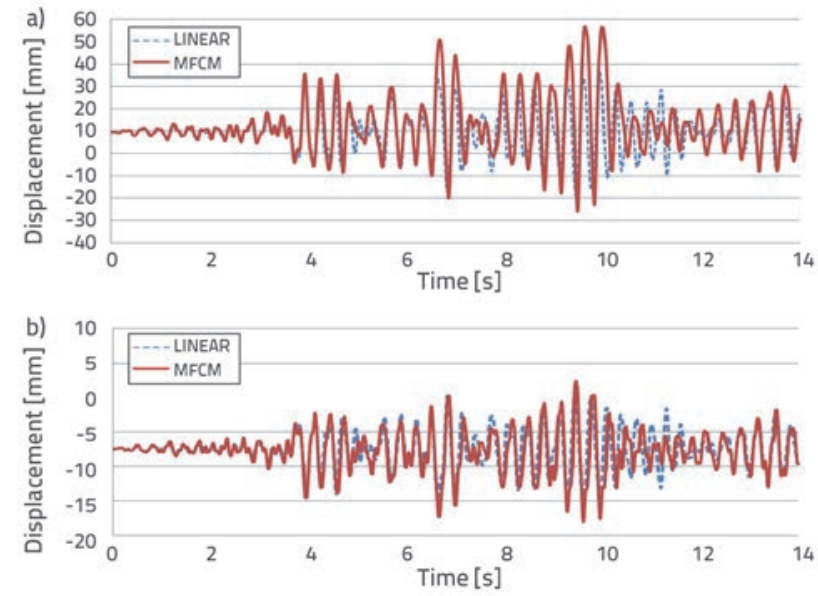

Figure 15. Crest displacement with empty reservoir (OMFCM): a) horizontal; b) vertical 

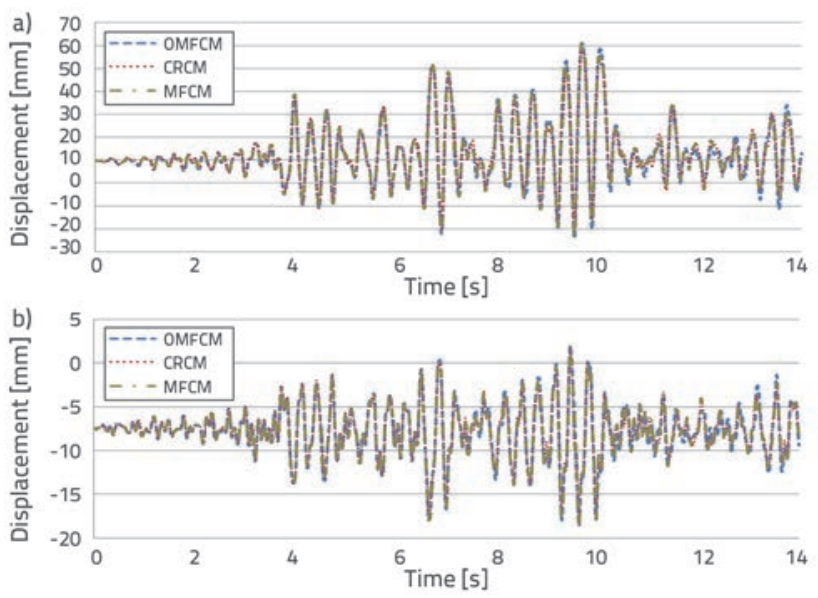

Figure 16. Crest displacement with empty reservoir MFCM model with threshold angle of $5^{\circ}, \mathrm{CRCM}$ and OMFCM: a) horizontal; b) vertical

No cracking occurs during at a relatively small ground motion. Near the slope change in the downstream face of dam, the
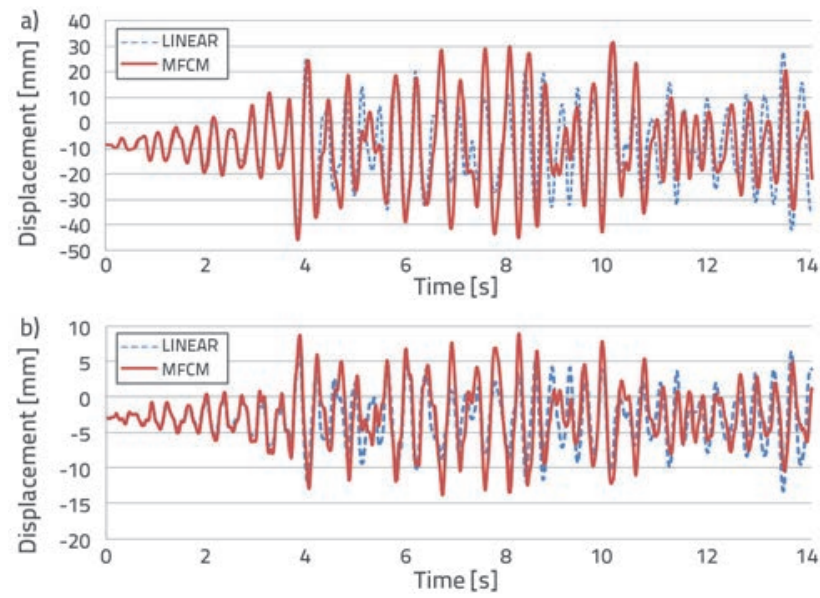

Figure 17. Crest displacement with impounded reservoir (MFCM) and with threshold angle $5^{\circ}$ : a) horizontal; b) vertical
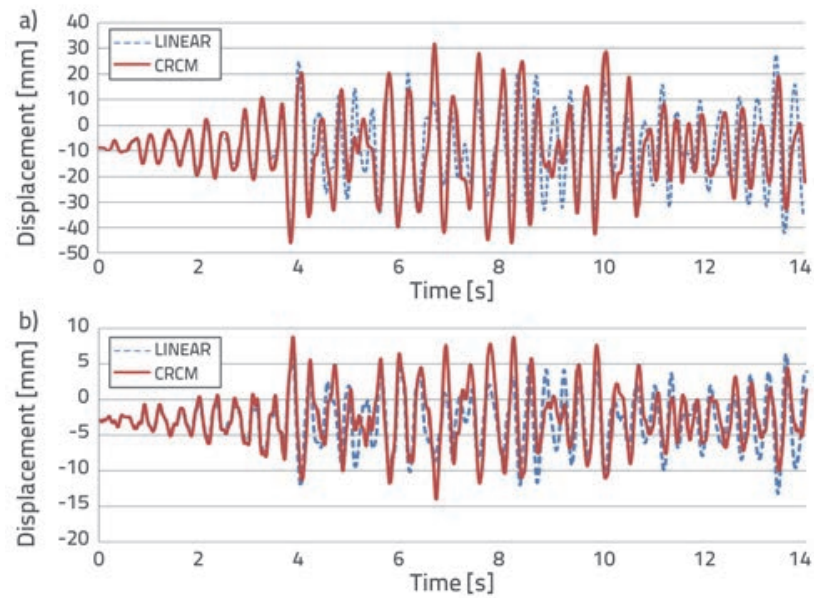

Figure 19. Crest displacement with impounded reservoir (CRCM): a) horizontal, b) vertical stresses reach the concrete tensile strength and the first crack appears in the dam at $3.934 \mathrm{sec}$.

The difference in displacement amplitudes reaches significant levels (especially between 6 and 8 and 9 and $11 \mathrm{sec}$ ) as the cracks penetrate inside of the dam. Figures 10 to 15 show that the elongation of the vibration period is obvious for crest displacements, and confirm that the crack propagation changes the vibration period of the dam. In the cracking model, the crest displacement is dominated by the rigid-body of the upper portion of the dam after the crack formation near the dam neck. The nonlinear response analyses show that the dams remain stable at all the times.

The displacement responses of different crack models, including MFCM with $5^{\circ}$ threshold angle, CRCM and OMFCM, are presented in Figure 16, where the results show that the differences between the responses are negligible.

Horizontal and vertical displacement responses of the dam crest, based on different crack models and considering the dam-reservoir interaction, are shown in Figures 17 to 20.

The results show that cracking in the dam first appears at 1.59
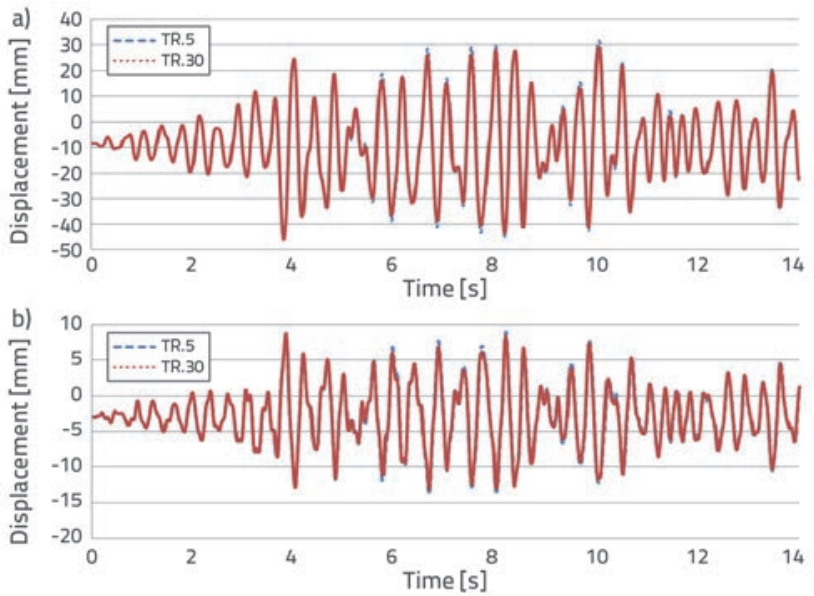

Figure 18. Crest displacement with impounded reservoir (MFCM) and with threshold angles $5^{\circ}, 30^{\circ}$ : a) horizontal, b) vertical
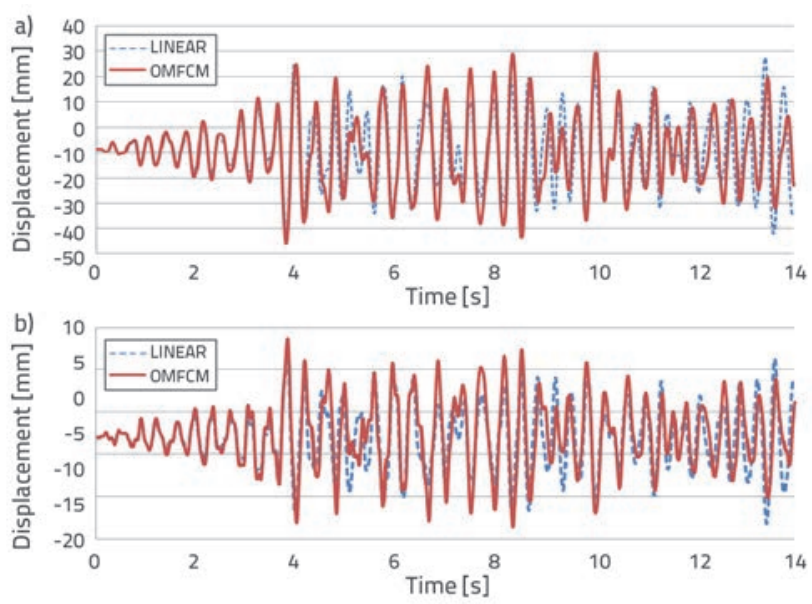

Figure 20. Crest displacement with impounded reservoir (OMFCM) a) horizontal, b) vertical 
sec at the heel of the dam base. As mentioned above, differences between displacement amplitudes increase between 6 and 10 sec as the cracks propagate within the dam body. Other results, such as changes in the vibration period and dam stability, are similar to the case of dam with an empty reservoir.

In Figures 21 to 23, the maximum and minimum principal stresses in the centre of the element 177 in the case of the dam with an empty reservoir are presented based on different crack models. Similar results are observed in Figures 24 to 26 and Figures 27 to 29 for the centre of the elements 177 and 8,

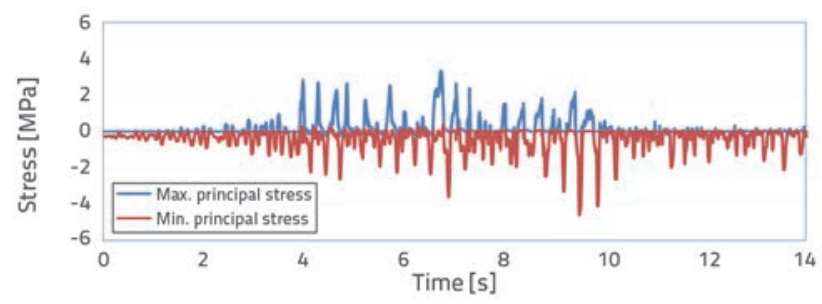

respectively, when the reservoir effect is considered.

Figure 21. Principal stresses of element 177 in dam with empty

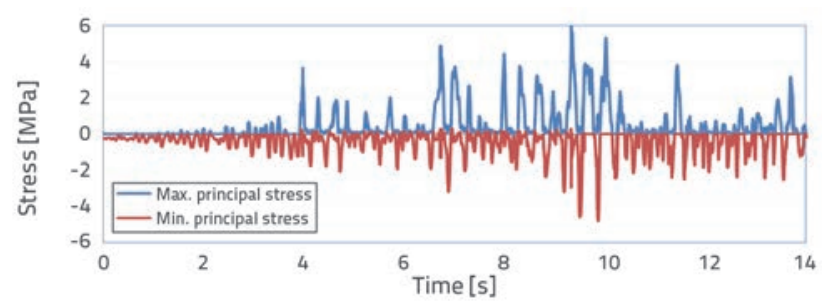

reservoir (CRCM)Slika

Figure 22. Principal stresses of element 177 in dam with empty
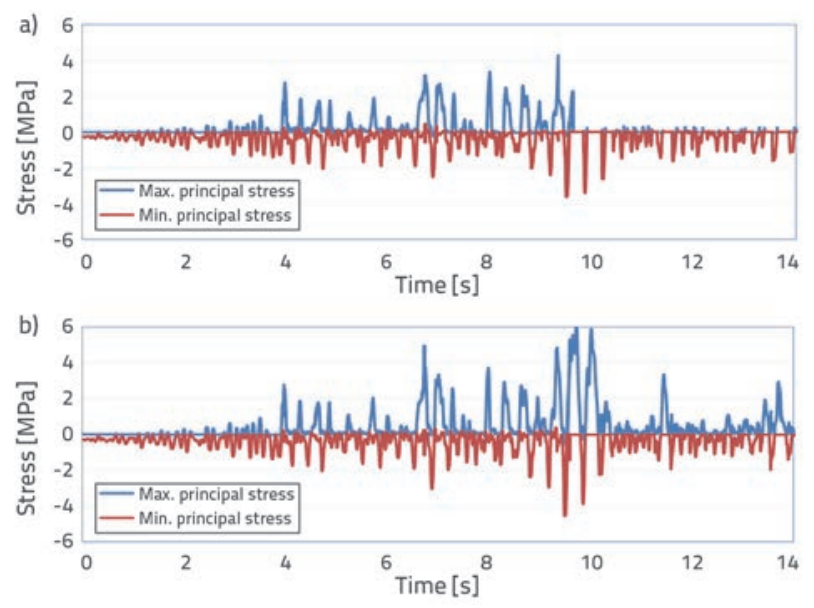

Figure 23. Principal stresses of element 177 in dam with empty Table 4. Number of cracked points in dam with empty reservoir effect reservoir (OMFCM)

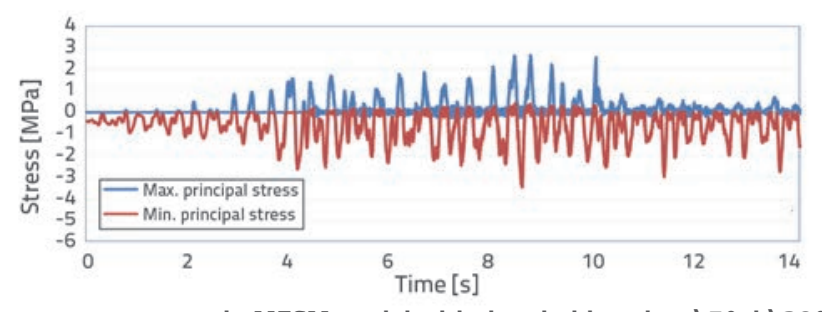

reservoir, MFCM model with threshold angle: a) $5^{\circ}$; b) $30^{\circ}$

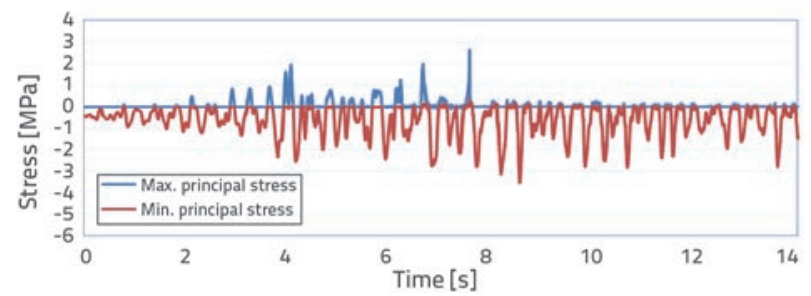

Figure 24. Principal stresses of element 177 in dam with impounded reservoir (OMFCM)
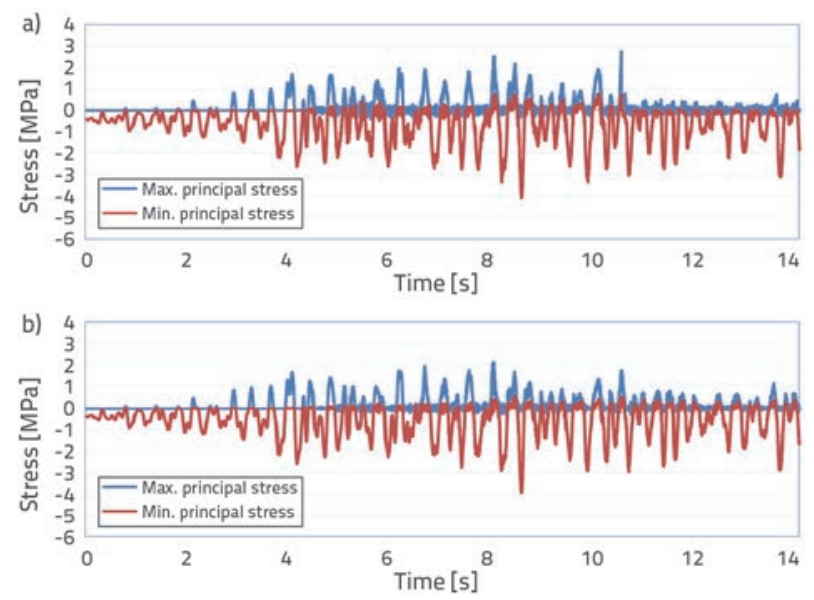

Figure 25. Principal stresses of element 177 in dam with impounded reservoir (CRCM)

Figure 26. Principal stresses of element 177 in dam with impounded

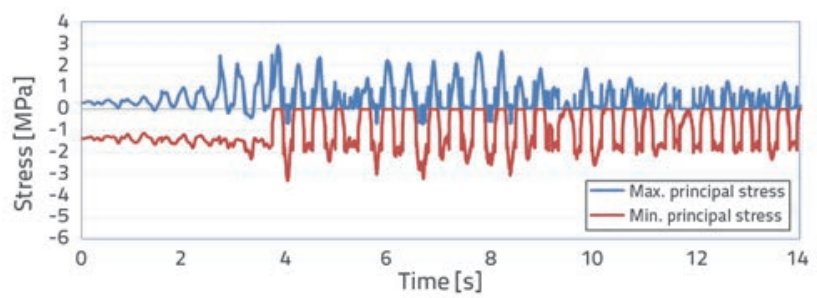

reservoir, MFCM model with threshold angle: a) $5^{\circ}$; b) $30^{\circ}$

Figure 27. Principal stresses of element 8 in dam with impounded

\begin{tabular}{|c|c|c|c|c|c|c|c|c|}
\hline & \multirow{2}{*}{ CRCM model } & \multirow{2}{*}{ OMFCM model } & \multicolumn{5}{|c|}{ MFCM model with threshold angle } \\
\cline { 3 - 9 } & & $\mathbf{5}^{\circ}$ & $\mathbf{1 0}^{\circ}$ & $\mathbf{1 5}^{\circ}$ & $\mathbf{2 0}^{\circ}$ & $\mathbf{2 5}^{\circ}$ & $\mathbf{3 0}^{\circ}$ \\
\hline First crack & 267 & 301 & 316 & 295 & 343 & 331 & 323 & 333 \\
\hline Second crack & - & 33 & 88 & 42 & 48 & 52 & 52 & 49 \\
\hline Third crack & - & - & 23 & 2 & - & - & - & - \\
\hline Fourth crack & - & - & 6 & 1 & - & - & - & - \\
\hline
\end{tabular}


Table 5. Number of cracked points in dam with impounded reservoir effect

\begin{tabular}{|c|c|c|c|c|c|c|c|c|}
\hline & \multirow{2}{*}{ CRCM model } & \multirow{2}{*}{ OMFCM model } & \multicolumn{5}{|c|}{ MFCM model with threshold angle } \\
\cline { 4 - 9 } & & & $\mathbf{5}^{\circ}$ & $\mathbf{1 0 ^ { \circ }}$ & $\mathbf{1 5}^{\circ}$ & $\mathbf{2 0}^{\circ}$ & $\mathbf{2 5}^{\circ}$ & $\mathbf{3 0}^{\circ}$ \\
\hline First crack & 208 & 157 & 197 & 184 & 188 & 201 & 153 & 176 \\
\hline Second crack & - & 28 & 72 & 56 & 63 & 43 & 34 & 37 \\
\hline Third crack & - & - & 43 & 28 & 21 & 12 & 7 & 1 \\
\hline Fourth crack & - & - & 19 & 10 & 6 & - & - & - \\
\hline
\end{tabular}
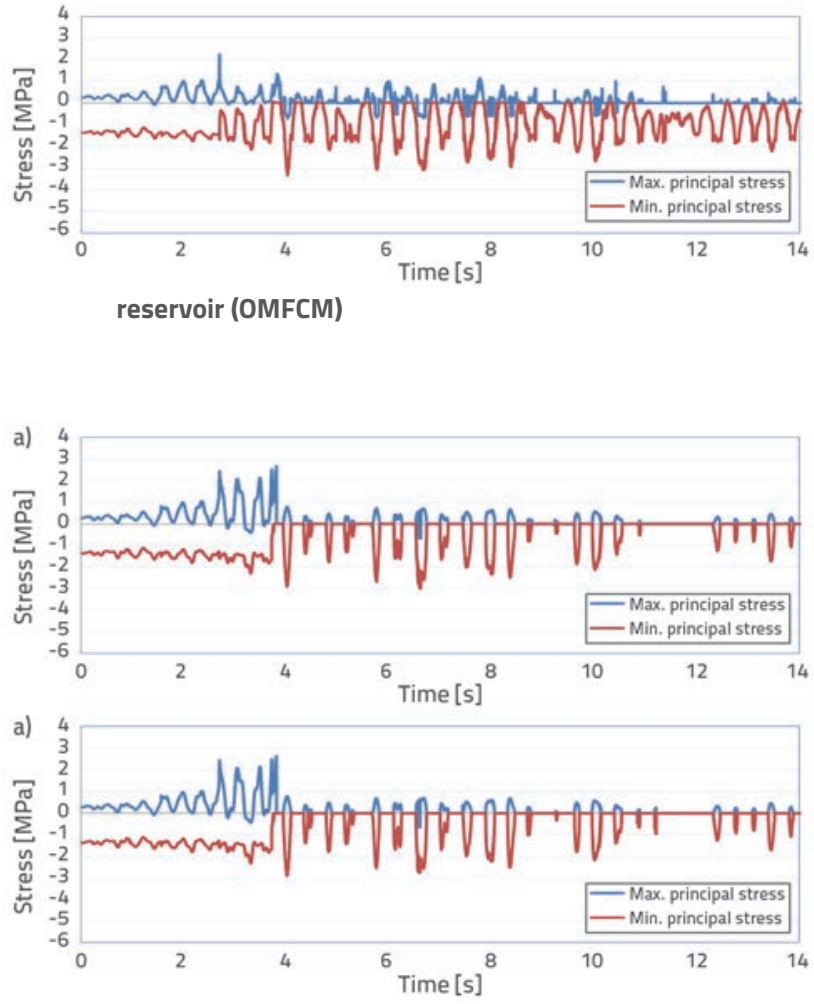

Figure 28. Principal stresses of element 8 in dam with impounded reservoir (CRCM)

Figure 29. Principal stresses of element 8 in dam with impounded reservoir, MFCM model with threshold angle: a) $5^{\circ}$; b) $30^{\circ}$

As shown in Figures 21 to 29, after the peak value of maximum principal stresses reaches the tensile strength of the concrete, cracking occurs in the gauss point, and its maximum tensile stresses decrease. For all smeared crack models, when the value of maximum principal stresses increases, then the minimum value of principal stresses decreases. In other words, cracking in the dams leads to redistribution of stresses.

As shown in Figure 21, by applying the CRCM model, the peak values of the maximum and minimum principal stresses are lower than those obtained by other models. In the OMFCM model (Figure 22), the peak values of the maximum principal stress are both qualitatively and quantitatively different from those of the CRCM model.

In Figure 23, for MFCM with the 30 degree threshold angle, at about $7 \mathrm{sec}$ and between 9 and $11 \mathrm{sec}$, the values of the maximum principal stresses are higher than the concrete tensile strength, which shows that tensile stress locking occurs at wider angles. Therefore, it is confirmed that the MFCM model with a large value of threshold angle is inappropriate for the nonlinear dam analysis.

Based on Figures 21 to 23, and in spite of the CRCM model, it can be seen that the tensile stress locking occurs in both the MFCM with the 30 degree threshold angle and the OMFCM model, and that the stress status in the MFCM with the 5 degree threshold angle is similar to the CRCM model.

After cracking, shear stresses cause rotation of principal axes and subsequently increase principal tensile stresses above the concrete tensile strength [35]. Accordingly, when the threshold angle assumes wider angles, then an increase of principal tensile stresses becomes more significant and the tensile stress-locking occurs. Therefore, the value of threshold angle should be limited to a certain angle to prevent stress-locking. Peak values of minimum principal stresses for the CRCM, OMFCM and MFCM models amount to 4.7, 4.9 and 3.7 MPa, respectively. In case of the dam with an impounded reservoir (Figures 24 to 29), results are similar to those observed for element 177 in the dam with an empty reservoir.

Tables 3 and 4 show the number of cracked points in all smeared-crack models. The results show that the second crack occurs at the OMFCM and MFCM crack models, and that, at the MFCM model with the threshold angles equal to 5 and 10 degrees, the third and fourth cracks can also be formed at some points of the elements that have become fully softened. In this research, the maximum number of cracked points in the MFCM model was observed at the threshold angle of 5 degrees. At wider threshold angles, the number of cracked points decreases, and as the number of cracks at a gauss point increases, the effect of these additional cracks on the result is significantly reduced.

Crack propagation within the dam, obtained by different smeared crack models, is schematically compared in Figures 30 and 31. Cracks opened in a gauss point of an element are indicated by red dots at point ordinates. As shown in these figures, different smeared crack models create a small difference in the cracking pattern.

In the dam with an empty reservoir, cracks initially appear near the slope change in the downstream face of the dam, and then penetrate deeper inside the dam. Subsequently, due to compressive stresses resulting from the top block weight of the dam, the cracking path deviates in a downward direction. Simultaneously with the propagation of these cracks, other 


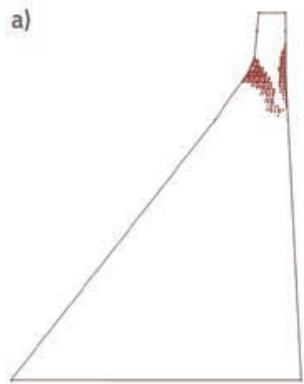

b)

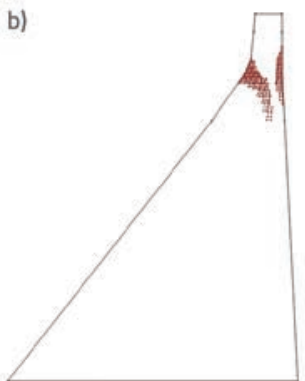

c)

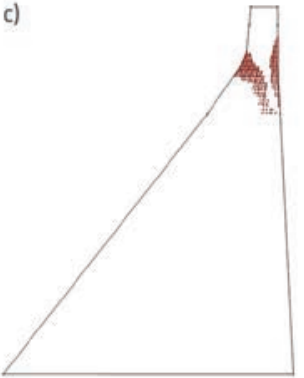

d)

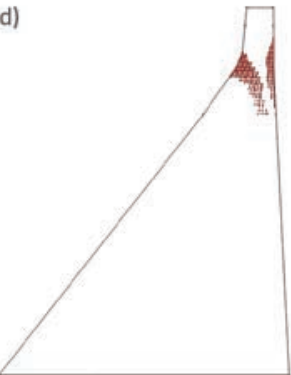

e)

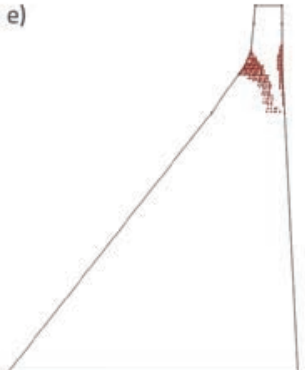

f)

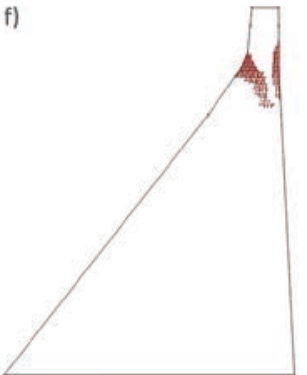

Figure 30. Distribution of cracks in dam with empty reservoir, without FSI effect: a) MFCM with threshold angle 5; b) MFCM with threshold angle 10; c) MFCM with threshold angle 15; d) MFCM with threshold angle 30; e) CRCM model; f) OMFCM model a)

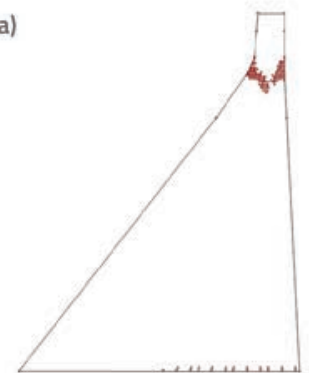

d)

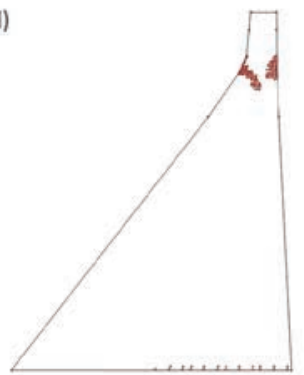

b)

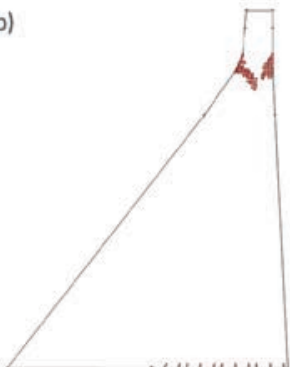

e)

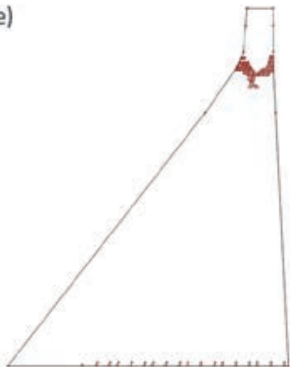

c)

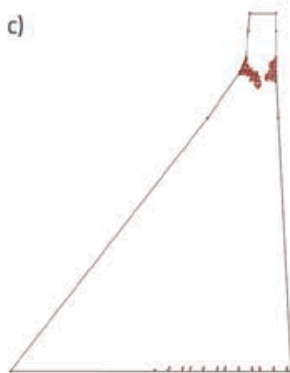

f)

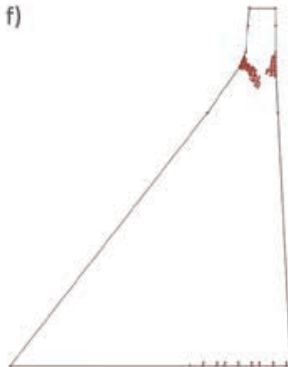

Figure 31. Distribution of cracks in dam with impounded reservoir, with FSI effect: a) MFCM with threshold angle 5; b) MFCM with threshold angle 10; c) MFCM with threshold angle 15; d) MFCM with threshold angle 30; e) CRCM model; f) OMFCM model

and completely cracked points can be closed and reopened at different times in dynamic analysis. The dam is able to retain its stability since it cannot undergo tensile stresses at the upstream and downstream faces at the same time.

The case of dam-reservoir, crack distributions, and deformed shape of the dam due to different smeared crack models, are presented in Figures 32 and 33 at different moments $(t=3.802$ sec and $t=10.02 \mathrm{sec}$ ). According to figures 17 to 20 and 32, the dam crest tends to move downstream and thus the cracking occurs in the region of dam heel. Furthermore, Figures 17 to 20 and 33 show that the dam suffers severe cracking in the upper part of the dam. The cracks at the downstream face and near the dam neck are opened, and so the upper part of the dam tends to become separated. Therefore, it can be observed that the cracking region is consistent with the deformed shape of the dam.

\section{Conclusion}

Different crack models have so far been presented because of the complex behaviour of cracked structures, such as concrete dams. The advantages and disadvantages of different crack models should be compared to obtain the most appropriate crack model. The nonlinear seismic response of the Pine Flat concrete gravity dam subjected to vertical and horizontal S69E component of Taft Lincoln is presented in this study. The dam-reservoir interaction is modelled using the finite element method and the Lagrangian approach. Nonlinear behaviour of concrete material is modelled using the nonlinear fracture mechanics based on the smeared crack concepts. Three smeared crack models are selected for concrete softening, and have successfully been used in the study of seismic response of the dam, in cracks also start to propagate at the upstream face of the dam (Figure 30). In case of a dam with an impounded reservoir, some cracks initially appear at the dam heel, and then they gradually propagate within the dam base. Subsequently, other cracks also start to penetrate into the dam body at the dam neck and at the downstream and upstream faces (Figure 31). Softened conjunction with the Bosak's time integration. In spite of quite extensive occurrence of cracks in the dam body, no dynamic instability was observed. Main conclusions of the analysis are:

- The response of dam crest in nonlinear analysis is different from that observed in linear analysis. These differences are due to the change of material behaviour 

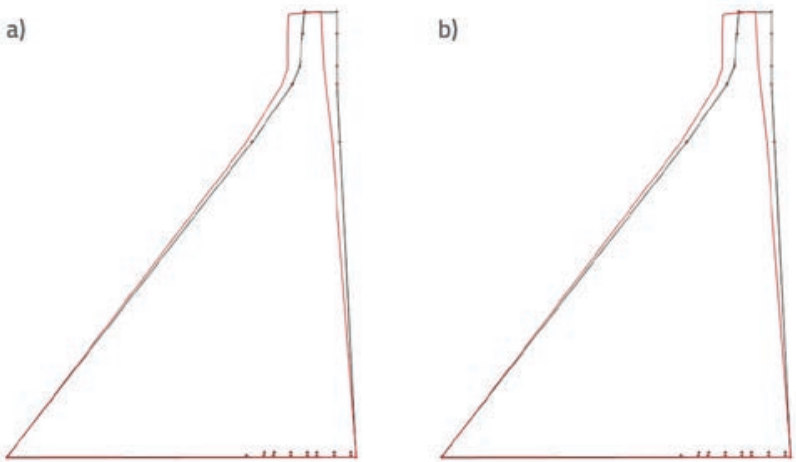

c)
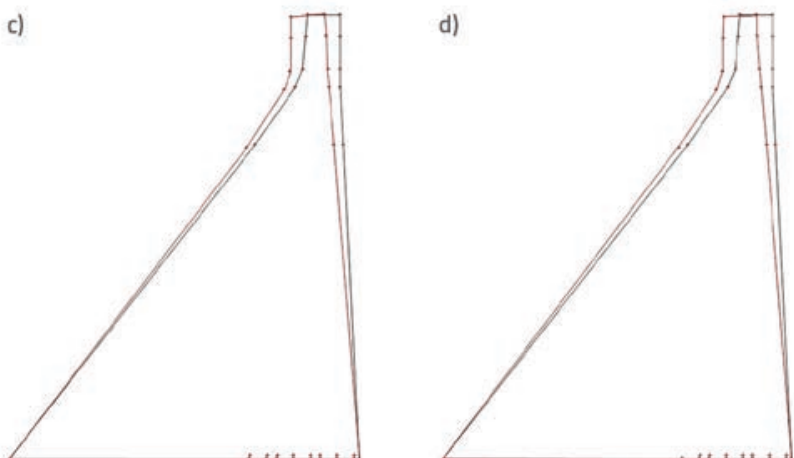

Figure 32. Distribution of cracks in the dam in case of included FSI effect ( $t=3.802$ sec): a) MFCM with threshold angle 5; b) MFCM with threshold angle 30; c) CRCM model; d) OMFCM model

after cracking.

- In all three crack models studied in the paper, the minimum value of principal stress decreases with an increase in the maximum principal stress value.

- In the MFCM model, the principal tensile stress increases with an increase in the shear stress in a gauss point of an element. Hence, the tensile stress locking effect is unrealistically provoked by the higher threshold angle.

- The MFCM model with a large value of threshold angle is not appropriate for stress calculation within the dam body.

\section{REFERENCES}

[1] Bettess, P., Zienkiewicz, O.C.: Coupled hydro-dynamic response of concrete gravity dam using finite and infinite elements, Earthquake Engineering and Structural Dynamics, 6 (1978), pp. 363-383, https://doi.org/10.1002/eqe.4290060404

[2] El-Aidi, B., Hall, J.F.: Nonlinear earthquake response of concrete gravity dams, part 1: modeling, Earthquake Engineering \& Structural Dynamics, 18 (1989), pp. 837-851, https://doi. org/10.1002/eqe.4290180607

[3] El-Aidi, B., Hall, J.F.: Nonlinear earthquake response of concrete gravity dams, part. 2: Behavior, Earthquake Engineering \& Structural Dynamics, 18 (1989), pp. 853-865, https://doi. org/10.1002/eqe.4290180608

[4] Navayi Neya, B.: Mathematical modelling of concrete gravity dams under earthquake loading considering construction joints, Ph.D thesis, Moscow Power Engineering Institute, 1998.

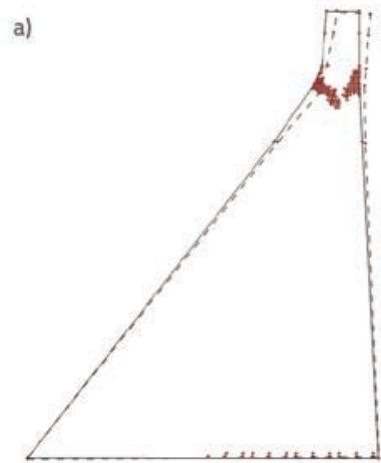

b)
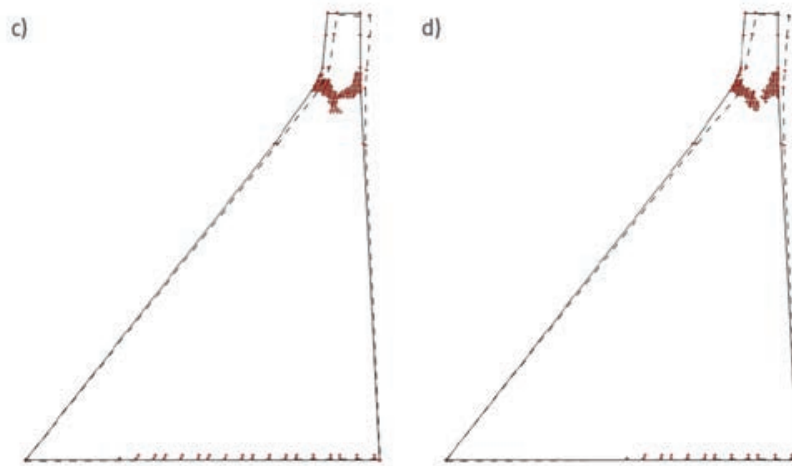

Figure 33. Distribution of cracks in dam if FSI effect is included ( $t=10.02$ sec): a) MFCM with threshold angle 5; b) MFCM with threshold angle 30; c) CRCM model; d) OMFCM model

- With respect to the results, the CRCM model represents a more realistic nonlinear behaviour of a concrete dam due to its more logical and accurate assessment of the stress status during crack propagation.

- The different crack modelling creates a small difference in crack propagation during earthquakes, whereat the final crack pattern of all three models does not differ substantially.

- The selection of the integration time algorithm (Bosak's time integration) is based on its ability to damp out highfrequency noise resulting from the impact of crack surfaces due to the opening and closing of cracks.

[5] Kalani Sarokolayi, L., Navayi Neya, B., Vaseghi Amiri, J.: Nonlinear dynamic analysis of concrete gravity dams considering rotational component of ground motion, Int. j. of civil engineering, 13 (2015), pp.16-29.

[6] Bhattacharjee, S.S., Leger, P.: Seismic cracking and energy dissipation in concrete gravity dams, Earthquake Engineering \& Structural Dynamics, 22 (1993), pp. 991-1007, https://doi. org/10.1002/eqe.4290221106

[7] Bhattacharjee, S.S., Leger, P.: Application of NLFM Models to Predict Cracking in Concrete Gravity Dams, Journal of Structural Engineering, ASCE, 120 (1994), pp. 1255-1271, https://doi. org/10.1061/(ASCE)0733-9445(1994)120:4(1255)

[8] Ayari, M.L.: Static and dynamic fracture echanics of concrete gravity dams, PhD thesis, Department of Civil, Environmental and Architectural Engineering, University of Colorado, Boulder, Colo, 1988. 
[9] Ahmadi, M.T., Razavi, S.: A three dimensional joint opening analysis of an arch dam, Comput. Struct., 44 (1992), pp. 187-192, https://doi.org/10.1016/0045-7949(92)90237-T

[10] Ahmadi, M.T., Izadinia, M., Bachmann, H.: A discrete crack joint model for nonlinear dynamic analysis of concrete arch dam, Comput. Struct., 79 (2001), pp. 403-420, https://doi.org/10.1016/ S0045-7949(00)00148-6

[11] Lotfi, V., Espandar, R.: Seismic analysis of concrete arch dams by combained discrete crack and non-orthogonal smeared crack technique, Eng. Struct., 26 (2004), pp. 27-37, https://doi. org/10.1016/j.engstruct.2003.08.007

[12] Gharib, F., Tinawi, R.: An application of damage mechanics for seismic analysis of concrete gravity dam, Earthquake Engineering and Structural Dynamics, 24 (1995), pp. 157-173, https://doi. org/10.1002/eqe.4290240203

[13] Gunn, R.M.: Nonlinear design and safety analysis of arch dams using damage mechanics, part 1: formulation, Hydropowers and dams, 2 (2001), pp. 64-74.

[14] Valliappan, S., Yazdchi, M., Khalili, N.: Earthquake analysis of gravity dams based on damage mechanics concept, International Journal for Numerical and Analytical Methods in Geomechanics, 20 (1996), pp. 725-751, https://doi.org/10.1002/(SICI)10969853(199610)20:10<725::AID-NAG843>3.0.CO;2-X

[15] Sumarac, D., Sekulovic, M., Krajcinovic, D.: Fracture of reinforced concrete beams subjected to three point bending, Int. J. Damage Mech., 12 (2003), pp. 31-44, https://doi. org/10.1177/1056789503012001002

[16] Labadi, Y., Hannachi, N.E.: Numerical simulation of brittle damage in concrete specimens, Strength Materials, 37 (2005), pp. 268281, https://doi.org/10.1007/s11223-005-0039-5

[17] Contrafatto, L., Cuomo, M.: A framework of elastic-plastic damaging model for concrete under multiaxial stress states, Int. J. Plast., 22 (2006), pp. 2272-2300, https://doi.org/10.1016/j. ijplas.2006.03.011

[18] Grassl, P., Jirasek, M.: Damage-plastic model for concrete failure, Int. J. Solids Struct., 43 (2006), pp. 7166-7196, https://doi. org/10.1016/j.ijsolstr.2006.06.032

[19] Khan, A.R., Al-Gadhib, A.H., Baluch, M.H.: Elasto-damage model for high strength concrete subjected to multiaxial loading, Int. J. Damage Mech., 16 (2007), pp. 361-398, https://doi. org/10.1177/1056789506065914

[20] Mirzabozorg, H., Ghaemian, M., Kianoush, M.R.: Damage mechanics approach in seismic analysis of concrete gravity dams including dam-reservoir interaction, Eur. Earthquake Eng., 18 (2004), pp. 17-24.

[21] Ardakanian, R., Ghaemian, M., Mirzabozorg, H.: Nonlinear behavior of mass concrete in $3-D$ problems using damage mechanics approach, Eur. Earthquake Eng., 2 (2006), pp. 65-89.

[22] Rashid, Y.R.: Analysis of prestressed concrete pressure vessels, Nuclear Engineering and Design, 7 (1968), pp. 334-344, https:// doi.org/10.1016/0029-5493(68)90066-6

[23] Bazant, Z.P., Oh, B.H.: Crack band theory for fracture of concrete. Materiaux et Constructions (Materials and Structures), 6 (1983), pp. 155-177, https://doi.org/10.1007/BF02486267

[24] Bazant, Z.P.: Mechanics of distributed crackings, ASME, Applied Mechanics Reviews, 39 (1986), pp. 675-705, https://doi. org/10.1115/1.314372

[25] Calayir, Y., Karaton, M.: Seismic Fracture Analysis of Concrete Gravity Dams including Dam-Reservoir Interaction, Computers and Structures, 83 (2005), pp. 1595-1606, https://doi. org/10.1016/j.compstruc.2005.02.003
[26] de Borst, R., Nauta, P.: Non-orthogonal cracks in a smeared finite element model, Engineering Computations, 2 (1985), pp. 35-46, https://doi.org/10.1108/eb023599

[27] Rots, J.G., de Borst, R.: Analysis of mixed-mode fracture in concrete, J. Engineering Mech. (ASCE), 113 (1987), pp. 1739-1758, https://doi.org/10.1061/(ASCE)0733-9399(1987)113:11(1739)

[28] Gupta, A.K., Akbar, H.: Cracking in reinforced concrete analysis, J. Struct. Engrg., ASCE, 110 (1984), pp. 1735-1746, https://doi. org/10.1061/(ASCE)0733-9445(1984)110:8(1735)

[29] Rots, J.G.: Smeared and discrete representations of localized fracture, Int. J. Fracture, 51 (1991), pp. 45-59, https://doi. org/10.1007/BF00020852

[30] Bazant, Z.P., Lin, F.B.: Nonlocal smeared cracking model for concrete fracture, J. Struct. Engrg., ASCE, 114 (1988), pp. 2493-2510, https://doi.org/10.1061/(ASCE)0733-9445(1988)114:11(2493)

[31] Ghaemian, M., Ghobarah, A.: Nonlinear Seismic Response of Concrete Gravity Dams with Dam-Reservoir Interaction, Journal of Engineering Structures, 21 (1999), pp. 306-315, https://doi. org/10.1016/S0141-0296(97)00208-3

[32] Ahmadi, M.T., Vaseghi Amiri J.: A new constitute model for nonlinear fracture analysis of concrete gravity dams including earthquake, International Journal of Engineering Science, 9 (1998), pp. 23-42. (In Persian).

[33] Weihe, S., Kroplin, B., de Borst, R.: Classification of smeared crack models based on material and structural properties, Int. J. Solids Struct., 35 (1998), pp. 1289-1308, https://doi.org/10.1016/ S0020-7683(97)00104-2

[34] Mosler, J., Meschke, G.: Embedded crack vs. smeared crack models: A comparison of elementwise discontinuous crack path approaches with emphasis on mesh bias, Comput. Methods Applied Mech. Eng., 193 (2004), pp. 3351-3375, https://doi. org/10.1016/j.cma.2003.09.022

[35] Cai., Q.: Finite element modeling of Cracking in gravity dams, PhD thesis, university of Pretoria, 2007.

[36] Espandar, R., Lotfi, V., Razaqpur, G.: Influence of effective parameters of non-orthogonal smeared crack approach in seismic response of concrete arch dams, Canadian Journal of Civil Engineering, 30 (2003), pp. 890-901, https://doi.org/10.1139/ 103-052

[37] Mirzabozorg, H., Ghaemian, M.: Nonlinear behavior of mass concrete in three-dimensional problems using smeared crack approach, Earthquake Eng. Struct. Dyn., 34 (2005), pp. 247-269, https://doi.org/10.1002/eqe.423

[38] Mirzabozorg, H., Khaloo, A.R., Ghaemian, M., Jalalzadeh, B.: Nonuniform cracking in smeared crack approach for seismic analysis of concrete dams in 3D space, Int. J. Earthquake Eng. Seism., 2 (2007), pp. 48-57.

[39] Mirzabozorg, H., Kianoush, M.R., Varmazyari M.: Nonlinear behavior of concrete gravity dams and effect of input spatially variation, Struct. Eng. Mech., 35 (2010), pp. 365-379, https://doi. org/10.12989/sem.2010.35.3.365

[40] Guanglun, W., Pekau, O.A., Chuhan, Z., Shaomin, W.: Seismic Fracture Analysis of Concrete Gravity Dams based on Nonlinear Fracture Mechanics, Engineering Fracture Mechanics, 65 (2000), pp. 67-87, https://doi.org/10.1016/S0013-7944(99)00104-6

[41] Chopra, A.K.: Earthquake behavior of reservoir-dam systems, Journal of the Engineering Mechanics Division, ASCE, No. EM6, 94 (1968), pp. 1475-1500. 